\title{
Controlled trial of mobilisation and manipulation for low back pain: hospital patients
}

\author{
H SIMS-WILLIAMS, M I V JAYSON，S M S YOUNG， H BADDELEY, E COLLINS
}

\section{Summary and conclusions}

Ninety-four patients with non-specific lumbar pain referred to hospital rheumatology and orthopaedic clinics participated in a double-blind controlled trial comparing mobilisation and manipulation with placebo physiotherapy. Results were assessed immediately after the treatment course, two months later, and at one year. Many patients showed improvement, but in contrast to a study on general-practitioner patients with nonspecific back pain no definite advantage could be associated with mobilisation and manipulation.

The benefits of mobilisation and manipulation for low back pain are probably restricted to hastening recovery in patients likely rapidly to improve spontaneously. Hence patients whose severity and duration of symptoms warrant specialist referral are less likely to benefit from the technique.

\section{Introduction}

Back problems probably constitute the most frequent causes of rheumatological disability. Although most attacks of back pain remit either spontaneously or after treatment, there is a high incidence of recurrence. Because of the variability in the course of symptoms, in any trial of treatment patients with differing degrees of problems must be considered separately. Elsewhere ${ }^{1}$ we have described the effects of mobilisation and manipulation ${ }^{2}$ in patients with non-specific back pain under the care of their general practitioners for whom a specialist opinion had not been sought. We now report on a similar trial directed at patients referred to hospital rheumatological or orthopaedic clinics because of non-specific back pain.

\section{Patients and methods}

We examined the referral letters of unselected patients attending hospital rheumatology and orthopaedic clinics. Patients referred because of lumbar pain were seen separately and considered for entry to the trial. After investigations and if there were no contraindications the patients were asked to attend for a four-week course of physiotherapy and for subsequent assessments. Contraindications excluding a patient from the trial were the same as before. ${ }^{1}$

Department of Medicine, University of Bristol, Bristol BS8 1TH H SIMS-WILLIAMS, $\mathrm{MB}$, CHB, research fellow

University of Manchester, Rheumatic Diseases Cuntre, Hope
Hospital, Salford M6 8HD Hospital, Salford M6 8HD
M I V JAYSON, MD, FRCP, professor of rheumatology

Bristol Royal Infirmary, Bristol BS2 8HW S M S YOUNG, MCSP, physiotherapist

University of Queensland, Australia

H BADDELEY, DMRD, FRCR, professor of radiology

University of Bath, Bath BA2 7AY

E COLLINS, BSC, statistician

Clinical assessments-The assessments were conducted by a physician who did not know whether the patient had been given active treatment or placebo physiotherapy. A detailed history was taken and examination performed with particular reference to the spine, and spinal movements and straight-leg raising were measured with a goniometer. ${ }^{3}$ Spinal radiographs were scored for degenerative changes. Assessments were repeated immediately after the four-week treatment course, two months later, and then by postal questionnaire at one year. Patients who failed to reply to the questionnaire were interviewed at home.

Treatment-Patients were allocated at random to either mobilisation and manipulation or placebo treatment. The form of mobilisation and manipulation of the spine was based on that described by Maitland ${ }^{2}$ and was administered by a physiotherapist specially experienced with the technique (SMSY). The treatment is commonly used in many physiotherapy departments and has been described. ${ }^{1}$ Placebo treatment was given by the same physiotherapist with comparable enthusiasm and consisted of microwave at the lowest possible setting directed to the lumbar spine for 15 minutes with the patient prone unless this caused pain. All treatments were given daily for the first week and then three times a week for a further three weeks. Treatment could be stopped earlier if the symptoms were relieved or if they progressed so that other investigations or treatment were indicated.

\section{Results}

Ninety-four patients entered the study, 48 of whom were allocated to receive mobilisation and manipulation and 46 to receive placebo treatment. The two groups were similar in mean age (active-treatment

\section{MINIPRINT TABLES I-VIII}

Im

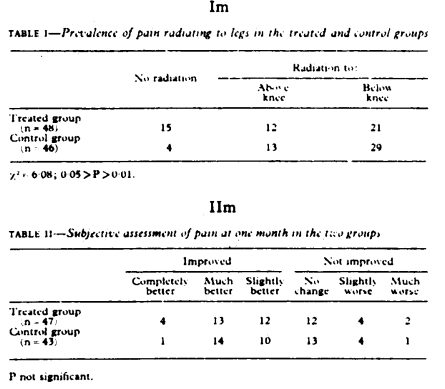

IIIm

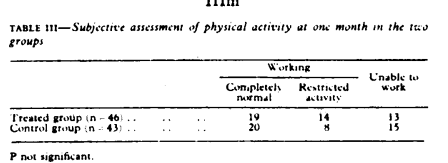

IVm

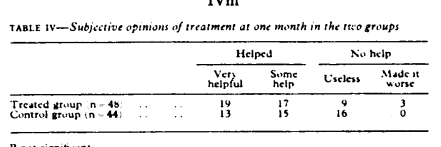

$\mathrm{Vm}$

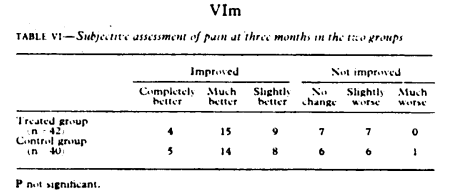

VIIm

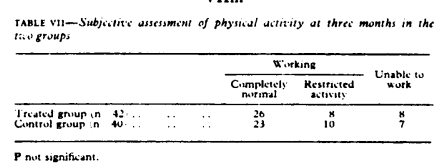

VIIIm

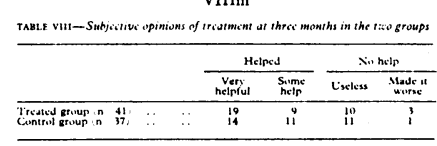

$P$ not significant. 
group $43.0 \mathrm{SD} 11.8$ years; controls $42.3 \pm 12.7$ years), sex distribution (M:F $31: 17$ and $24: 22$ ), marital state, physical activity, duration of back pain, obvious factors precipitating pain, sudden or gradual onset of pain, stiffness of spine, aggravation by raising intrathoracic pressure, night pain, analgesic intake, and spinal movements. Radiation of pain into the legs, however, was significantly less prevalent in the treated group than in the controls $\left(\chi^{2}=6.08 ; 0.05>\mathbf{P}>0.01\right)$ (table Im (miniprint)).

\section{ONE-MONTH ASSESSMENT}

Ninety-two patients attended for follow-up immediately after the course of treatment. Most patients in each group thought that their symptoms were improved (table IIm), that they were better able to perform physical activity (table IIIm), and that their treatment whether active or placebo was helpful (table IVm). There were no significant differences between the two groups in any of these variables. Table Vm shows the difference in spinal movements compared with initial values. There was no change in flexion, but highly significant increases in extension were noted in both groups (active-treatment group $\mathrm{P}<0.005$; controls $\mathrm{P}<0.001$ ). There were no alterations in lateral flexion to either side. Right and left straight-leg raising improved significantly in the active-treatment group $(P<0.05$ and $\mathbf{P}=0.05$ ) but not in the controls (table $\mathrm{Vm}$ ).

The overall impression was that immediately after treatment most patients in each group were better. These improvements were similar in both groups, except for straight-leg raising, which increased on both sides in the active-treatment group.

THREE-MONTH ASSESSMENT

Eighty-two patients were reassessed two months after the end of the treatment. In both groups most patients were still improved (table VIm), were performing at least light work (table VIIm),

\section{MINIPRINT TABLES IX-XVIII}

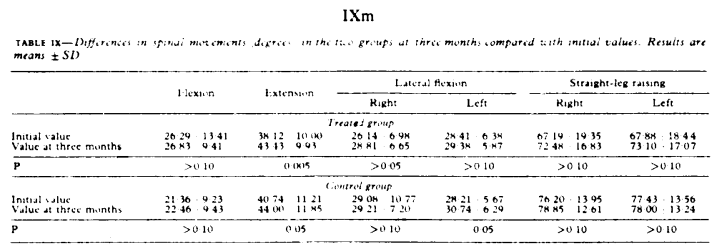

$\mathrm{xm}$

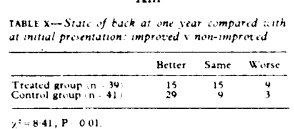

$\mathrm{XIm}$

XIIm

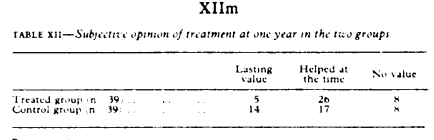$$
\text { Pnit , ignit }
$$$$
\text { xiIIm }
$$

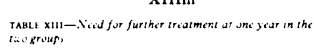

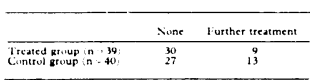$$
\text { P not signticant. }
$$

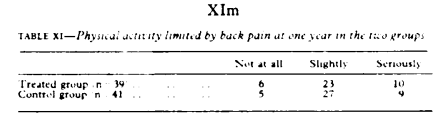

XIVm

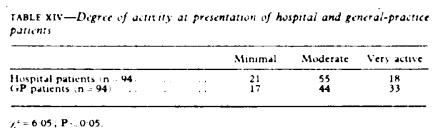

$\mathrm{XVm}$
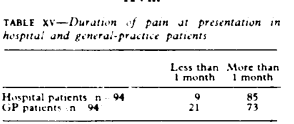

XVIm
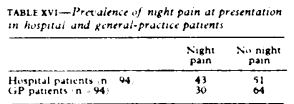

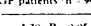

XVIIm
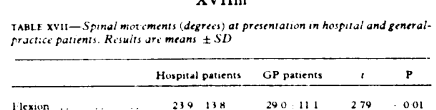

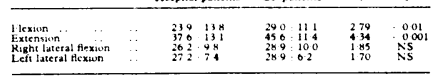
NS $=$ Net signiticant.

XVIIIm

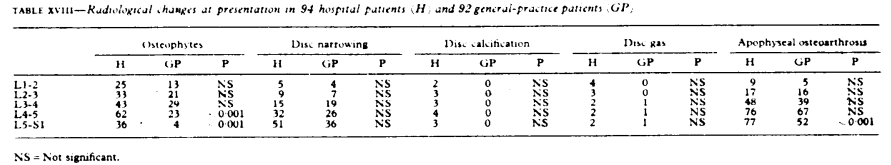

and thought that their treatment was helpful (table VIIIm). The incidences of improvement were similar in the two groups. Neither group showed any change in spinal flexion, but both showed significant improvements in extension (treated group $\mathrm{P}<0.005$; controls $P<0.05)$. There were no alterations in lateral flexion to the right in either group or in lateral flexion to the left in the active-treatment group. The controls, however, showed a significant improvement in lateral flexion to the left $(P<0.05)$. Right and left straight-leg raising increased in both groups and to a greater extent in the active-treatment group than the controls, but the changes were not significant (table IXm).

These results suggest that most patients in each group were better and that mobilisation and manipulation made no difference to outcome.

\section{ONE-YEAR ASSESSMENT}

Information was obtained by postal questionnaire or interview at home from 80 patients. About half thought that their backs were better than when first seen, but this was significantly more common among the controls $\left(\chi^{2}=8.41 ; \mathrm{P}<0.01\right)$ (table $\mathrm{Xm}$ ). There were no significant differences between the groups in limitation of physical activity (table XIm), subjective opinion of the value of treatment (table XIIm), and need for further treatment excluding physiotherapy (table XIIIm). There was no evidence that mobilisation and manipulation produced any long-term benefit.

Analysis of the clinical and radiographic data obtained at presentation in those who achieved the best and worst results at one year failed to yield any prognostic markers.

\section{HOSPITAL VERSUS GENERAL-PRACTITIONER SERIES}

We compared the data on presentation in the present trial with those obtained in our general-practice series. ${ }^{1}$ The two groups of patients were similar in sex distribution, marital state, obvious factors precipitating pain, sudden or gradual onset of symptoms, stiffness of spine, aggravation by raising intrathoracic pressure, radiation into the legs, and straight-leg raising. The hospital patients, however, were significantly older (mean age $42.63 \pm$ SD 12.22 years $v 37 \cdot 18 \pm$ 11.88 years; $t=3.08, \quad \mathrm{P}<0.005)$; more frequently restricted in activity $\left(\chi^{2}=6.05 ; P<0.05\right)$ (cable $X I V m$ ); had a longer duration of pain $\left(\gamma^{2}=4.80 ; P<0.05\right)$ (table $\left.X V m\right) ;$ more often suffered from night pain $\left(\chi^{2}=4.30 ; \mathrm{P}<0.05\right)$ (table $\mathrm{XVIm}$ ); had greater restriction of certain spinal movements (flexion $t=2 \cdot 79, \mathrm{P}<0.01$; extension $t=4.34, \mathrm{P}<0.001$ ) (table XVIIm); and radiologically showed higher incidences of osteophytes around the L4-5 and L5-S1 discs $(P<0.001)$ and apophyseal joint osteoarthrosis at L5-S1 $(\mathbf{P}<0.001)$ (table XVIIIm).

\section{Discussion}

The management of non-specific back pain is unsatisfactory, and physiotherapy is often prescribed empirically. The form of treatment used here was based on that prescribed by Maitland ${ }^{2}$ and is in general use for low back pain. There are many other forms of mobilisation and manipulation, which may be practised in different ways by physicians, surgeons, physiotherapists, and other practitioners. As with any practical procedure there is scope for much individual variation. Clearly, caution is indicated in drawing broad conclusions on the values of mobilisation and manipulation from any study.

In our other study ${ }^{1}$ we compared mobilisation and manipulation with placebo physiotherapy for patients presenting to their general practitioner with back pain sufficient to warrant spinal radiography. We found that most patients improved but that immediately after treatment there were small but definite advantages in favour of mobilisation and manipulation. These differences were less pronounced two months later, and at one year there were no differences between the two groups. Patients who did best were those with the shorter duration of symptoms.

In the present trial of mobilisation and manipulation compared with placebo physiotherapy we failed to identify at any stage any real advantage for patients referred to hospital rheumatology 
and orthopaedic clinics. Patients referred for a specialist opinion may be expected to have a longer duration of symptoms than general-practitioner patients, and this was confirmed from our data. Several other features, however, were identified as being significantly worse in this group of patients. Mobilisation and manipulation probably hasten improvements that are likely to occur anyway. Our failure to show any benefit from mobilisation and manipulation in this series was probably due to the patients likely to benefit being those most likely to improve spontaneously and being selected out by the delay before being seen.

We thank Mr K Lucas and Mr P Stableforth for allowing us to see patients under their care. This study was performed with the aid of a grant from the Department of Health and Social Security, to whom we are most grateful.

Requests for reprints should be sent to Professor M I V Jayson.

\section{References}

${ }^{1}$ Sims-Williams, H, et al, British Medical fournal, 1978, 2, 1338.

2 Maitland, G D, Vertebral Manipulation, 4th edn. London, Butterworths, 1977.

${ }^{3}$ Loebl, W Y, Annals of Physical Medicine, 1967, 9, 103.

${ }^{4}$ Reynolds, P M G, Rheumatology and Rehabilitation, 1975, 14, 180.

(Accepted 11 September 1979)

\title{
Bacterial contamination of expressed breast milk
}

\author{
CATRYN LLOYD JONES, R F JENNISON, S W D'SOUZA
}

British Medical fournal, 1979, 2, 1320-1322

\section{Summary and conclusions}

In a study of breast milk collected into sterile bottles rinsed in $1 \%$ hypochlorite solution the hypochlorite solution adherent to the sides of the bottles apparently caused a large reduction in bacterial contamination of the milk after storage at $4^{\circ} \mathrm{C}$ for up to four hours. Heating expressed breast milk at $62 \cdot 5^{\circ} \mathrm{C}$ for five minutes destroyed over $90 \%$ of the Escherichia coli, Staphylococcus aureus, and group $B$ beta-haemolytic streptococci inoculated into the milk samples.

Rinsing collecting bottles with hypochlorite solution may be valuable in collecting milk with a low bacterial content for human-milk banks. Furthermore, the currently accepted pasteurisation time of 30 minutes may be excessive.

\section{Introduction}

The protective effect of breast-feeding against infection has been recognised for many years, particularly in relation to enteric diseases. Conserving the anti-infective properties of breast milk and providing milk that is not contaminated by pathogenic bacteria, however, pose practical problems of collection and storage. At present, milk stored in breast-milk banks has been sterilised, boiled, or, more commonly, pasteurised at the standard $62.5^{\circ} \mathrm{C}$ for 30 minutes to destroy any pathogenic bacteria. Nevertheless, heating the milk in this way affects certain protective substances such as IgA and lactoferrin. ${ }^{1}$ Hence the less severe the heat treatment the greater the chance that these substances will be conserved. We undertook the present study to find whether the standard pasteurisation time of 30 minutes is excessive for making expressed breast milk bacteriologically safe. The organisms studied were the pathogenic bacteria found

St Mary's Hospital, Manchester M13 0JH

CATRYN LLOYD JONES, BSC, research student, university department of child health

R F JENNISON, MD, FRCPATH, consultant clinical pathologist

S W D'SOUZA, PHD, MRCP, senior lecturer in child health and consultant paediatrician by Lucas and Roberts ${ }^{2}$ to be growing in untreated human milknamely, Escherichia coli, Staphylococcus aureus, and group B $\beta$-haemolytic streptococci. Lucas and Roberts ${ }^{2}$ also reported that milk collected in vessels rinsed in hypochlorite solution contained fewer bacteria than milk collected in vessels washed in ordinary detergent. We investigated this further to find whether the hypochlorite solution adhering to the sides of the vessels acted in a bacteriostatic way.

\section{Methods}

Expressed breast milk was donated by mothers who had given birth at this hospital. Each donor was instructed on how to collect the milk hygienically, which included washing the hands and breasts before collection.

Rinsing collecting bottles with hypochlorite solution-Each donor was given two identical $20 \mathrm{ml}$ glass bottles with screw caps, both bottles having been autoclaved at $121^{\circ} \mathrm{C}$. One bottle served as a control and the other has been washed in $1 \%(\mathrm{w} / \mathrm{v})$ sodium hypochlorite solution (Milton Crystals). The donor expressed about $10 \mathrm{ml}$ milk from the same breast into each bottle. To avoid bias when doing bacterial counts the investigator (CLJ) was not told which bottles had been washed in hypochlorite solution. Viable bacterial counts were carried out on paired samples of milk within four hours of collection, during which time the milk was stored at $4^{\circ} \mathrm{C}$.

Heating at $62.5^{\circ} \mathrm{C}$-Expressed breast-milk samples $(15-20 \mathrm{ml})$ were collected in similar glass bottles to those that had been autoclaved and rinsed in hypochlorite solution. The milk was stored in a refrigerator, and within four hours of collection an aliquot was inoculated with either $E$ coli, Staph aureus, or group B $\beta$-haemolytic streptococci. A concentration of about $10^{6}$ organisms $/ \mathrm{ml}$ was decided as sufficient. The inoculated milk $(7.5 \mathrm{ml})$ was heated in a waterbath at $62 \cdot 5 \pm 0 \cdot 1{ }^{\circ} \mathrm{C}$ and viable bacterial counts carried out at intervals of five, 10, 20, and 30 minutes. Inoculated agar plates were incubated for 14 hours at $37^{\circ} \mathrm{C}$. This procedure was repeated six times for each pathogen and the percentage destruction of bacteria after heating calculated.

Preparation of inoculum-Brown's tubes for standardising bacterial vaccines were used. The bacterial suspension was diluted to $10^{7.5}$ organisms $/ \mathrm{ml}$, and $1 \mathrm{ml}$ of this suspension then diluted in $6.5 \mathrm{ml}$ breast milk to give a suspension of about $10^{6}$ organisms $/ \mathrm{ml}$.

Viable bacterial counts were carried out by the Miles and Misra method, as described by Baker and Breach ${ }^{3}$ and Cruickshank et al.

\section{Results}

Effect of hypochlorite solution on bacterial contamination-Milk collected in ordinary sterile bottles had higher bacterial counts than 